\title{
The Propensity of a Science-Based Discipline towards Surface Learning Compared to the Arts-A Fresh Look at Two Cultures
}

\author{
Warren Lake1, William Boyd', Wendy Boyd ${ }^{2}$ \\ ${ }^{1}$ School of Environment, Science \& Engineering, Southern Cross University, Lismore, Australia \\ ${ }^{2}$ School of Education, Southern Cross University, Lismore, Australia \\ Email: warren.lake@scu.edu.au,william.boyd@scu.edu.au, wendy.boyd@scu.edu.au
}

Received 14 August 2015; accepted 13 September 2015; published 16 September 2015

Copyright (C) 2015 by authors and Scientific Research Publishing Inc.

This work is licensed under the Creative Commons Attribution International License (CC BY). http://creativecommons.org/licenses/by/4.0/

(c) (i) Open Access

\section{Abstract}

The propensity of science students towards surface and deep learning approaches was investigated to determine whether they were more likely to be encouraged toward a surface rather than deep approach to learning: more specifically do undergraduate environmental science students favour a surface approach to a greater extent than students in other disciplines such as the arts. Examining whether a discipline favours towards students adopting a particular approach to learning, this study surveyed over $\mathbf{5 0 0}$ undergraduate students across seven discipline areas at one university to examine patterns of learning approaches. Analysis of scores reflected tendencies towards surface and deep approaches: motivations and strategies indicated that environmental science students do not adopt a significantly different overall approach compared to students in all other disciplines, apart from a greater tendency towards a surface approach on the main scale and surface strategy subscale compared, specifically, to arts and social science. The findings appear to indicate that both the Schools of Arts \& Social Science and Environment, Science \& Engineering, while multi-disciplinary in nature, may still show apparent remnants of "two cultures".

\section{Keywords}

Study Processes Questionnaire (SPQ), R-SPQ-2F, Discipline, Environmental Science, Science, Art, Two Cultures

\section{Introduction}

In the two decades following 1960, there was considerable debate over whether university teaching in the arts

How to cite this paper: Lake, W., Boyd, W., \& Boyd, W. (2015). The Propensity of a Science-Based Discipline towards Surface Learning Compared to the Arts-A Fresh Look at Two Cultures. Creative Education, 6, 1733-1741. 
and the sciences had become highly specialised, resulting in the notion that these two disciplines had developed their own separate cultures of learning (Williamson, 2011). Indeed the concept of two cultures or distinctive domains of human knowledge that have become dominant, or inaccessible to each other, has long been a concern of philosophers and researchers (Snow, 2012). Snow (2012), for example, comments that: “...it was common for [students] to start concentrating wholly upon science subjects or humanities subjects from as early as 14 years old, to study only three of these subjects between sixteen and eighteen, and then concentrate exclusively upon one while at university" (p. 16). The pattern of subject choice amongst students generates a cultural divide between those who choose to study the sciences and those who choose to study the arts or the humanities. The engrained nature of this divide during the 20th century was evidenced by the tendency for students to specialise in one particular subject domain such as the science or the arts. The differences between the two domains, in modern terms, is well explained by Williamson (2011), who states that, "the domains of arts and sciences are different in their aims [in that] science aims to explain natural observable processes in the world while the arts aim to interpret the world through the expression of the artist” (p. 42). Williamson, interestingly, continued to comment that, "whether this has a detrimental effect on the learning approach a student takes and more importantly academic performance remains to be seen”. This paper addresses this very question.

Despite the specifics of how teaching in these two fields developed over time, higher education research continues to recognize that different subject areas, by their very nature, can and often produce differences in the context of learning (Ramsden, 1997). To this point, Ramsden (1997) further indicates that the effects of the learning context on students in each discipline are most notable when comparing "the arts" and "the sciences". It may be argued that divergence of arts and sciences fields was inevitable, given that it has been established that students in different disciplines adopt different study approaches; science students, notably, are more likely to develop a surface approach to learning, compared to other disciplines such as arts and education (Newble \& Clarke, 1986; Biggs, 1987a; Ramsden, 1997). Regardless of the findings of this research, such differences have more recently been brought into question, in part due to changes in the educational system over the last few decades (Williamson, 2011). Given that content knowledge is conceptualized through the lens of declarative and procedural knowledge structures (Luft et al., 2015), the question remains whether science-based students are appropriately exposed to comprehension aspects of learning that enable higher-order learning such as declarative knowledge. To this point, regardless of disciplinary factors, it is thought that for a student to develop sound conceptual knowledge in science requires the integration of the student's prior knowledge with domain specific knowledge (Chin \& Brown, 2000). This includes facts and concepts that work in conjunction with core concepts to produce conceptual understanding (Luft et al., 2015). Research specific to learning in science indicates that students tend to engage in more meaningful learning when they actively monitor and reflect on the process of learning, as well as approach their studies purposefully by evaluating the results of their own learning efforts (Chin \& Brown, 2000).

While studies such as those by Ramsden \& Entwistle (1981) and Ramsden (1997) appear to indicate that academic departments (schools) can affect the type of approach a student will adopt, before such assumptions can be made in a contemporary context, other factors need to be considered. Past research has consistently identified differences in the type of approach to learning taken by both the arts and science subject areas (e.g. Watkins \& Hattie, 1981; Biggs, 1987a; Ramsden 1997; Kember, 2000; Pike \& Killian, 2001). Specifically, research undertaken by Kember (2000) indicated that memorisation, which is often used as a psychometric component in many learning approach measurement tools, such as Biggs' (1987b) Study Process Questionnaire (SPQ), can occur in conjunction with the intention of a student to understand. This is in contrast to its intended use for related questions in the SPQ tool, as a contribution to the surface approach scale. More importantly, science students appear to resort to rote learning more readily compared to arts students (Watkins \& Hattie, 1981; Kember, 2000), especially if they perceive it is a requirement of the course and assessment (Kember, 2000). Given these notions, it is not easy to make the assumption that arts-based schools necessarily produce deeper learners, or that science-based disciplines inevitably favour seemingly undesirable surface learning approaches.

More generally, Regan (1996) pointed out that the meaning of the surface and deep approach distinction is equally applicable to all disciplines, likely reflecting differences in the ways of thinking in those disciplines. Regan (1996) further commented that it is useful to interpret the Study Process Questionnaire specifically within the context of each subject area. Peculiar to the aims of this paper, an important question to consider is how the culture of a discipline area leads to the adoption of particular learning approach. Biggs \& Tang (2007) speculate 
that this operates through the way a course is structured, both in terms of teaching and assessment. This study, by looking at the motives and strategies that are commonly measured in the Revised Study Process Questionnaire (R-SPQ-2F), attempts to identify notable patterns and to ascertain if patterns identified in the past appear to persist.

The extent to which students identify with a particular discipline and its impact on their learning approach have also been considered by various researchers, with recent findings indicating that student perceptions of what approach to learning is believed to be taken by other students in their discipline area, shown to influence their own learning approach (Bliuc, Ellis, Goodyear, \& Hendres, 2011a, 2011b; Smyth, Mavor, Platow, Grace, \& Reynolds, 2015).

Given recent and continuing changes in student demographics and the changing nature of higher education (i.e. Kasworm, 2003; Siemens \& Matheos, 2012), it is timely to reinvestigate earlier findings in light of contemporary data. Additionally, such a study opens up the opportunity to reinvestigate whether this difference between schools in terms of the type of approach students tend to adopt to learning is still obvious, as was determined by earlier studies using learning approach measurement tools, and to discuss whether it is acceptable in terms of the type of students engaged in applied science-based schools focusing on fields such as environmental science.

\section{Methodology}

This study adopted Biggs et al.'s (2001) most recent version of his Study Processes Questionnaire (R-SPQ-2F), a 20-question self-reporting questionnaire that uses a 5 point Likert scale format to help assess students in terms of their approaches to learning. It does this through the identification of scale scores regarding motives and strategies. The questionnaire provides the researcher with scores on motives (five questions on each motive measuring deep and surface motives used by the participant) and two scores on strategies (five questions on each strategy measuring deep and surface strategies used by the participant). This inventory tool is best summarised in the following way: Deep Approach (DA) = Deep Motive (DM) + Deep Strategy (DS). Surface Approach (SA) $=$ Surface Motive $(\mathrm{SA})+$ Surface Strategy (SA).

The questionnaire formed the basis of an online survey, using the Qualtrics online survey tool, which targeted all schools at Southern Cross University (Ethics approval ECN-13-214). Southern Cross University is typical of the new generation of universities emerging in many countries and evolving out of previous binary education systems. It, therefore, provides a relevant case study, which in turn provides insight into the issues of student learning approaches across disciplinary boundaries, especially where those disciplines tend to be applied in nature, and where they adhere less closely to the conventional disciplinary boundaries found in older-established universities. The findings, therefore, are generalisable beyond this case study, and will provide a frame for further case studies at other institutions.

A series of emails were sent out to all students currently enrolled at the University alerting students to the survey. The survey consisted of the original questions from Biggs' R-SPQ-2F survey, plus additional questions regarding age, gender, current grade point average (GPA), whether students consider themselves to be mature age students, in what school they study, and the degree they were undertaking. In this paper we focus on the school in which they study. Comparisons of the seven schools (Education, Law \& Justice, Health \& Human Science, Business, Arts \& Social Science, Tourism \& Hospitality, and Environment, Science \& Engineering) were first made using ANOVA to evaluate the differences between the two main scale scores of deep and surface approach. Analysis included the examination of the subscale components of motivation and strategy indicators, to determine school patterns of approach for each school, namely deep motive, deep strategy, surface motive, and surface strategy. Post-hoc tests (Bonferroni-Holm) were also performed to look for patterns that were not specified a priori.

It should be noted that the focus on the student's school provides a proxy for discipline. Our university has, in common with many new generation universities, a focus on program driven institutional curricula. This presents difficulties in disciplinary research, especially in terms of aligning schools and degree courses with traditional discipline definitions. While the university programs are largely focused on recognisable individual disciplinary areas. Conventionally, research regarding learning approaches look at differences between disciplines rather than between schools. However, despite the tendency towards to transdisciplinary approaches in programs, the individual Schools tend towards conventional scholarly disciplines, and so the disciplinary culture of each 
School can be equated to relevant conventional scholarly disciplines. The University in this study has recognizable discipline areas typical of each school that can be seen as close equivalents to conventional scholarly disciplines. Table 1 provides a summary of the University's Schools and descriptions that were surveyed for this study.

\section{Results}

\subsection{Comparison of Main Scales for Each School}

Arts \& Social Science students scored both the highest mean deep approach score and the lowest mean score for surface approach (Figure 1). The null hypotheses for deep approach $(\mathrm{F}(6,496)=3.14, P<0.05)$ and surface approach $(\mathrm{F}(6,496)=4.57, \mathrm{P}<0.05)$ were not rejected, and therefore, post-hoc tests were required (Table 2).

Testing for significant differences between schools for deep approach indicated that the Environment, Science \& Engineering $(\mathrm{M}=31.7, \mathrm{SD}=7.1, \mathrm{n}=57)$, Education $(\mathrm{M}=30.46, \mathrm{SD}=7.76, \mathrm{n}=58)$, Tourism \& Hospitality $(\mathrm{M}=33.4, \mathrm{SD}=6.66, \mathrm{n}=28)$, and Law \& Justice $(\mathrm{M}=32.09, \mathrm{SD}=7.4, \mathrm{n}=73)$ did not have any significant differences with any other school. However, the Arts \& Social Science $(M=34.23, S D=7.52, n=78)$ had a statistically higher score than both Health \& Human Science $(\mathrm{M}=30.33, \mathrm{SD}=7.26, \mathrm{n}=117)$ and Business $(\mathrm{M}$ $=30.25, \mathrm{SD}=8.36, \mathrm{n}=90$ ) for deep approach.

Testing for significant differences between schools for surface approach indicated that Education $(M=20.27$,

Table 1. School and proxy descriptions.

\begin{tabular}{lll}
\hline School & Description & Proxy for \\
\hline $\begin{array}{ll}\text { Environmental Science \& Engineering } \\
\text { Education }\end{array}$ & $\begin{array}{l}\text { Predominately applied science, some social } \\
\text { science and some engineering. }\end{array}$ & Applied science \\
Arts \& Social Science & Mixture of arts and social science & Arts \& Social Science \\
Health \& Human Science & Mixture of arts and social science & Arts \& Social Science \\
Law \& Justice & Applied science & Applied science \\
Tourism \& Hospitality Management & Mixture of arts and social science & Arts \& Social Science \\
Business & Mixture of management and social science & Social science \\
\hline
\end{tabular}

${ }^{a}$ The Engineering discipline is new for the School of Environmental Science and Engineering, with a very small portion of the results from the School $(\mathrm{N}=57)$, coming from engineering $(\mathrm{n}=5)$.

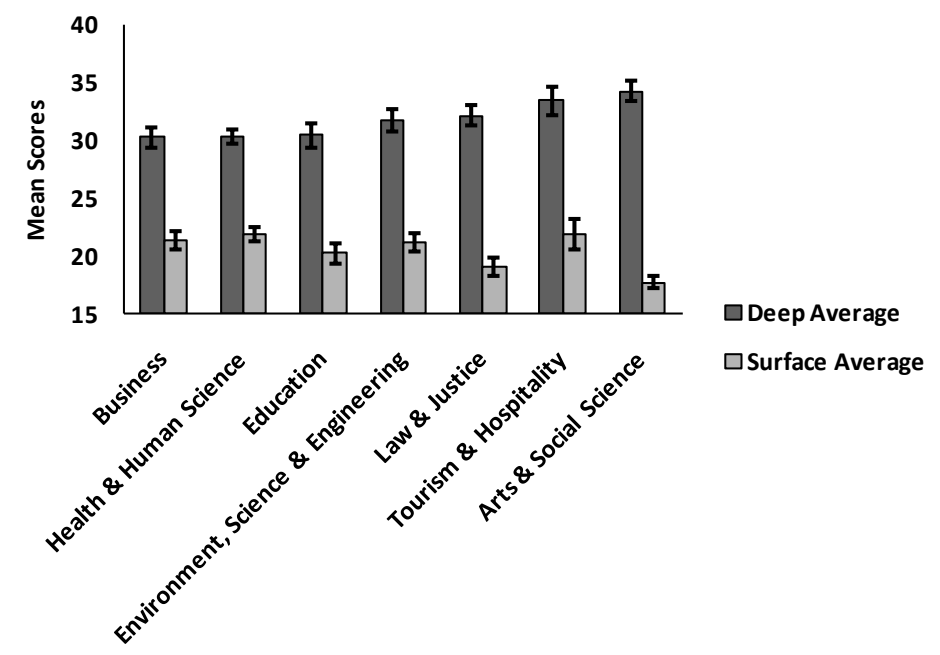

Figure 1. Mean deep and surface approach scores for each school $(\mathrm{N}=$ 496). Error bars indicate \pm one standard error. 
Table 2. Post-hoc test: Bonferroni-Holm testing for significant differences between schools for deep approach. Only those comparisons with significant differences are listed.

\begin{tabular}{|c|c|c|c|c|}
\hline \multicolumn{5}{|c|}{ Deep approach } \\
\hline Group 1 & Group 2 & Critical & $P$ & Sig \\
\hline Health \& Human Science & Arts \& Social Science & 0.002381 & 0.000377 & Yes \\
\hline Business & Arts \& Social Science & 0.0025 & 0.001556 & Yes \\
\hline \multicolumn{5}{|c|}{ Surface approach } \\
\hline Group 1 & Group 2 & Critical & $P$ & Sig \\
\hline Health \& Human Science & Arts \& Social Science & 0.002381 & $<0.000$ & Yes \\
\hline Business & Arts \& Social Science & 0.0025 & 0.000258 & Yes \\
\hline Environment, Science \& Engineering & Arts \& Social Science & 0.002632 & 0.000504 & Yes \\
\hline Arts \& Social Science & Tourism & 0.002777 & 0.001188 & Yes \\
\hline
\end{tabular}

$\mathrm{SD}=6.4, \mathrm{n}=58)$, and Law \& Justice $(\mathrm{M}=19.09$, SD 6.29, $\mathrm{n}=73)$ did not have significant differences with any other school. However, Arts \& Social Science $(M=17.78, S D=5.15, n=78)$ had a statistically lower score than Environmental Science \& Engineering $(M=21.24, S D=6.1, n=57)$, Health \& Human Science $(M=$ 21.85, $\mathrm{SD}=6.38, \mathrm{n}=117)$, Business $(\mathrm{M}=21.42, \mathrm{SD}=7.14, \mathrm{n}=90)$, and Tourism \& Hospitality $(\mathrm{M}=21.92$, SD $6.85, n=28$ ) for surface approaches to learning.

\subsection{Comparison of Subscales for Each School (Deep Subscales)}

Arts \& Social Science students scored the highest mean deep approach score for deep motive, with the scores ranging from 15.26 to 17.73 and mean scores for deep strategy ranging from 14.65 to 16.75 . Tourism \& Hospitality scored the highest individual score for deep strategy $(\mathrm{M}=16.75, \mathrm{SD}=3.99)$, slightly higher than Arts \& Social Science $(\mathrm{M}=16.5, \mathrm{SD}=4.11)$ (Figure 2$)$. The null hypotheses were rejected for both deep motive ( $\mathrm{F}(6$, $496)=3.53, P<0.1)$ and deep strategy $(\mathrm{F}(6,496)=2.40, P<0.5)$. Post-hoc tests, therefore, were required (Table 3).

In terms of deep motive, Arts \& Social Science $(M=17.73, S D=3.97)$ had a significantly higher score compared with Business $(M=15.26, S D=4.35)$ and Health \& Human Science $(M=15.68, S D=3.67)$.

In terms of deep strategy, after post-hoc tests, no significant differences were identified between any schools on this strategy.

\subsection{Comparison of Subscales for Each School (Surface Subscales)}

The mean scores of each school for surface motive ranged from 7.88 to 9.53 and for surface strategy from 9.89 to 12.78 (Figure 3). Arts \& Social Science scored the lowest mean score for surface motive. In terms of surface strategy, the mean score for Tourism and Hospitality represented the highest mean score of all groups, with Arts and Social Science scoring the lowest mean score. The null hypotheses were rejected for both surface motive $(\mathrm{F}(6,496)=6.37, P<0.1)$ and surface strategy $(\mathrm{F}(6,496)=3.31, P<0.5)$, and therefore post-hoc tests were required (Table 4).

Surface motive showed a significant difference between Business $(M=9.53, S D=3.92)$ and Arts \& Social Science $(M=7.88, S D=2.43)$. No other significant differences were found for surface motive. There was significant difference for surface strategy between Arts \& Social Science $(M=9.89, S D=3.17)$ and each of Health \& Human Science $(\mathrm{M}=12.74, \mathrm{SD}=3.64)$, Environment, Science \& Engineering $(\mathrm{M}=12.22, \mathrm{SD}=3.46)$, Tourism \& Hospitality $(\mathrm{M}=12.79, \mathrm{SD}=4.16)$, and Business $(\mathrm{M}=11.89, \mathrm{SD}=3.74)$ and between Health \& Human Science, and Law \& Justice ( $\mathrm{M}=10.74, \mathrm{SD}=3.79)$.

\section{Discussion}

In an earlier Australian study, Watkins \& Hattie (1981) found that science students infrequently appear to 


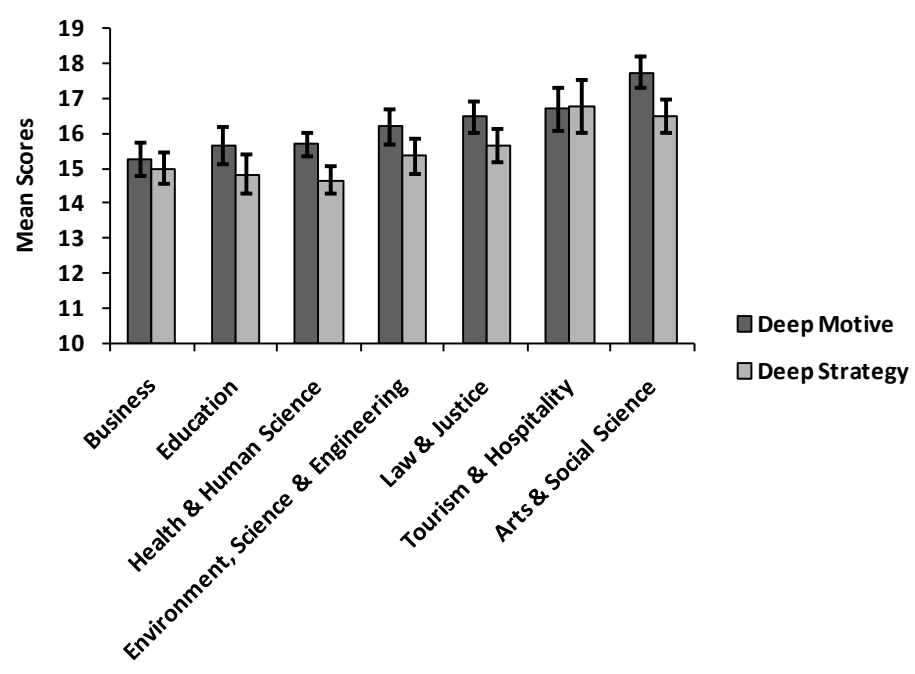

Figure 2. Mean deep motivation and deep strategy scores of all schools. Error bars indicate \pm one standard error.

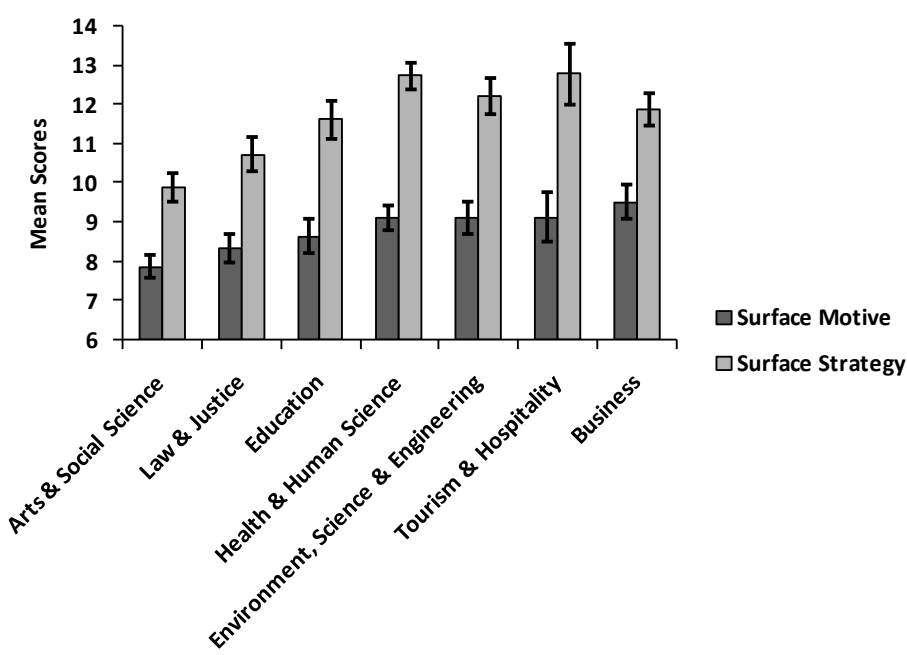

Figure 3. Mean surface motivation and surface strategy scores all schools. Error bars indicate \pm one standard error.

Table 3. Posthoc test of differences of deep motivation and deep strategy scores between schools (Bonferroni-Holm). Only those comparisons with significant differences are listed.

\begin{tabular}{ccccc}
\hline & \multicolumn{2}{c}{ Deep motive } & & Sig \\
\hline Group 1 & Group 2 & Critical & $P$ & Yes \\
\hline Business & Arts \& Social Science & 0.002381 & 0.000182 & Yes \\
\hline Health \& Human Science & Arts \& Social Science & 0.0025 & 0.000274 & \\
\hline \multicolumn{2}{c}{ Deep Strategy } \\
\hline
\end{tabular}

adopt the deep-level study approaches which were correlated with a higher grade point average. However, in our study, putting grade point average aside, very few differences regarding the adoption of deep approach to learning were identified between schools. More specifically, differences between the School of Environment, Science \& Engineering, a proxy for applied science, and all other schools, some of which include those that are a proxy 
Table 4. Post-hoc test of differences of surface motivation and surface strategy scores between schools (Bonferroni-Holm). Only those comparisons with significant differences are listed.

\begin{tabular}{|c|c|c|c|c|}
\hline \multicolumn{5}{|c|}{ Deep approach } \\
\hline Group 1 & Group 2 & Critical & $P$ & Sig \\
\hline Business & Arts \& Social Science & 0.002381 & 0.001578 & Yes \\
\hline \multicolumn{5}{|c|}{ Surface approach } \\
\hline Group 1 & Group 2 & Critical & $P$ & Sig \\
\hline Health \& Human Science & Arts \& Social Science & 0.002381 & $<0.000$ & Yes \\
\hline Environment, Science \& Engineering & Arts \& Social Science & 0.0025 & $<0.000$ & Yes \\
\hline Arts \& Social Science & Tourism \& Hospitality & 0.002632 & 0.000252 & Yes \\
\hline Business & Arts \& Social Science & 0.002778 & 0.000305 & Yes \\
\hline Health \& Human Science & Law \& Justice & 0.002941 & 0.000359 & Yes \\
\hline
\end{tabular}

for the arts, were not statistically significant. However, Arts \& Social Science had the highest mean score for deep approach compared to all other schools, but was only statistically significant when compared to both Health \& Human Science, and Business. Apart from these, deep approach to learning does not appear to vary greatly between other schools. Based on previous research specific to learning approaches, such as Biggs (1987a), this result was not unexpected, as his study identified differences between the arts and the sciences in terms of a higher surface approach score and not a higher deep approach score for science students compared to arts students.

The results for surface approach, however, produced more differences, heavily featuring Arts \& Social Science having a significantly lower score than Environment, Science \& Engineering, Health \& Human Science, Business, and Tourism \& Hospitality. This falls unsurprisingly into the narrative of Biggs (1987a), in which differences in approach between the two disciplines are more pronounced in terms of surface approach. Again, in all cases, Arts \& Social Science outperformed the other schools by scoring lower on surface approach. This appears to support the notion that science students would be more likely to develop a surface approach, as per previous work regarding science, compared to the arts (Biggs, 1987a).

As to why this difference occurs, Ramsden (1997) indicates that science students are more likely to stress an over-concentration on techniques and procedural details, which promote a surface approach. Additionally when contrasting arts and science disciplines, he indicates that there are systematic differences in students' perceptions of appropriate ways of learning, and that, “... some students may be handicapped in the development and use of both operation and comprehension learning styles by the dominant culture of the discipline in which they are being trained" (Ramsden, 1997: p. 215). In the case of this study, although the differences between these disciplines is based on schools as a proxy for these disciplines, these factors should be given appropriate consideration, as they could at least in part explain these reported differences.

The results appear to indicate that, in a contemporary sense, even though there is more of a focus on inter-disciplinary programs at universities such as ours, schools that are heavily weighted towards science may still show some remnants of factors that promote a surface approach to learning. However, these findings, although indicating an important difference, should be looked at in a deeper context, more specifically by looking at the differences between schools in terms of the subscales motives and strategies of both deep and surface approaches.

In terms of the deep subscales, specifically deep motive, Arts \& Social Science had a significantly higher score compared with Business and Health \& Human Science, while there were no significant differences identified between any other schools on deep strategy. This suggests that arts-weighted subjects have students that are no more motivated than students from science-weighted subjects. More specifically, given that no significant difference between Arts \& Social Science students and Environment Science \& Engineering students was found, the suggestion by Biggs (1987a) that the most intrinsically motivated students were more likely to be enrolled in arts rather than science has little strength in a contemporary sense. However, before completely dismissing this 
idea, it is important to test whether differences are apparent on the surface motive subscale. On this point, scores on surface motive were significantly different between Business and Arts \& Social Science, but not significant between any other schools, giving strength to the idea that intrinsically motivated students are no more likely to be enrolled in arts compared to science.

Patterns of surface strategy scores, on the other hand, indicated a significant difference between Arts \& Social Science and all other schools except Law \& Justice. This suggests that the difference between arts and science proxies have been heavily influenced by the surface strategy. When reflecting on these trends and statistical differences, we find that the school of Arts and Social Science is only different to the School of Environment, Science \& Engineering in terms of surface approach and more specifically on the strategies adopted. These findings, may also indicate as Baxter \& Poullaos (2009) discusses, that science and arts students may score differently because they have adapted in a different way in terms of approach to learning in their respective school. Furthermore, the findings may also indicate that both the Schools of Arts \& Social Science and Environment, Science \& Engineering, while multi-disciplinary in nature, still show apparent remnants of Snow's (2012) “two cultures”, which, to an extent, supports the notion that science students are more likely to develop a surface approach to learning.

\section{Conclusion}

In this study, we found that the School for Arts and Social Science (as a proxy for the arts) is only different to the School of Environment, Science \& Engineering (as a proxy for science) in terms of surface approach and, more specifically, on the strategy subscale. This supports the notion that science students are more likely to adopt a surface approach to learning. However, it is important to note that in terms of deep approach to learning, there were no significant differences on the deep approach scale. These findings suggest that science and arts students may score differently because they have adapted in different ways in terms of approach to learning, particularly in terms of learning strategies within the programs of their respective Schools. Furthermore, the findings also suggest that both the Schools of Arts \& Social Science and Environment, Science \& Engineering, while multi-disciplinary in nature, still retain apparent remnants of Snow’s (2012) “two cultures”.

\section{References}

Baxter, J., \& Poullaos, C. (2009). Practices, Profession and Pedagogy in Accounting: Essays in Honour of Bill Birkett. Sydney: Sydney University Press.

Biggs, J. (1987a). Student Approaches to Learning and Studying. Research Monograph.

Biggs, J. (1987b). Study Process Questionnaire. Hawthorn, Vic: ACER.

Biggs, J., \& Tang, C. (2007). Using Constructive Alignment in Outcomes-Based Teaching and Learning Teaching for Quality Learning at University (3rd ed., pp. 50-63). Maidenhead: Open University Press.

Biggs, J., Kember, D., \& Leung, D. Y. (2001). The Revised Two-Factor Study Process Questionnaire: R-SPQ-2F. The British Journal of Educational Psychology, 71, 133-149. http://dx.doi.org/10.1348/000709901158433

Bliuc, A.-M., Ellis, R. A., Goodyear, P., \& Hendres, D. M. (2011a). The Role of Social Identification as University Student in Learning: Relationships between Students' Social Identity, Approaches to Learning, and Academic Achievement. Educational Psychology, 31, 559-574. http://dx.doi.org/10.1080/01443410.2011.585948

Bliuc, A.-M., Ellis, R. A., Goodyear, P., \& Hendres, D. M. (2011b). Understanding Student Learning in Context: Relationships between University Students' Social Identity, Approaches to Learning, and Academic Performance. European Journal of Psychology of Education, 26, 417-433. http://dx.doi.org/10.1007/s10212-011-0065-6

Chin, C., \& Brown, D. E. (2000). Learning in Science: A Comparison of Deep and Surface Approaches. Journal of Research in Science Teaching, 37, 109-138. http://dx.doi.org/10.1002/(SICI)1098-2736(200002)37:2<109::AID-TEA3>3.0.CO;2-7

Kasworm, C. E. (2003). Setting the Stage: Adults in Higher Education. New Directions for Student Services, $2003,3-10$. http://dx.doi.org/10.1002/ss.83

Kember, D. (2000). Misconceptions about the Learning Approaches, Motivation and Study Practices of Asian Students. Higher Education, 40, 99-121. http://dx.doi.org/10.1023/A:1004036826490

Luft, J., Hill, K., Nixon, R., Campbell, B., \& Dubois, S. (2015). The Knowledge Needed to Teach Science: Approaches, Implications, and Potential Research. Paper Presented at the Annual Meeting of ASTE. Portland, OR.

Newble, D. I., \& Clarke, R. M. (1986). The Approaches to Learning of Students in a Traditional and in an Innovative Problem-Based Medical School. Medical Education, 20, 267-273. http://dx.doi.org/10.1111/j.1365-2923.1986.tb01365.x 
Pike, G. R., \& Killian, T. S. (2001). Reported Gains in Student Learning: Do Academic Disciplines Make a Difference? Research in Higher Education, 42, 429-454. http://dx.doi.org/10.1023/A:1011054825704

Ramsden, P. (1997). The Context of Learning in Academic Departments. The Experience of Learning, 2, 198-216.

Ramsden, P., \& Entwistle, N. J. (1981). Effects of Academic Departments on Students' Approaches to Studying. British Journal of Educational Psychology, 51, 368-383. http://dx.doi.org/10.1111/j.2044-8279.1981.tb02493.x

Regan, J. (1996). First-Year Southern Cross University Students’ Approaches to Learning and Studying: A Replication Study. Unpublished Thesis (MEd), Lismore: Southern Cross University.

Siemens, G., \& Matheos, K. (2012). Systemic Changes in Higher Education. In Education, 16, 3-18.

Smyth, L., Mavor, K. I., Platow, M. J., Grace, D. M., \& Reynolds, K. J. (2015). Discipline Social Identification, Study Norms and Learning Approach in University Students. Educational Psychology, 35, 53-72. http://dx.doi.org/10.1080/01443410.2013.822962

Snow, C. P. (2012). The Two Cultures. Cambridge, UK: Cambridge University Press.

Watkins, D., \& Hattie, J. (1981). The Learning Processes of Australian University Students: Investigations of Contextual and Personological Factors. British Journal of Educational Psychology, 51, 384-393. http://dx.doi.org/10.1111/j.2044-8279.1981.tb02494.x

Williamson, P. K. (2011). The Creative Problem Solving Skills of Arts and Science Students—The Two Cultures Debate Revisited. Thinking Skills and Creativity, 6, 31-43. http://dx.doi.org/10.1016/j.tsc.2010.08.001 